\title{
Transitions in the lives of young people with complex healthcare needs
}

\author{
S. Kirk \\ School of Nursing, Midwifery and Social Work, University of Manchester, Manchester, UK \\ Accepted for publication 17 April 2008
}

\section{Keywords}

chronic illness, complex

healthcare needs,

disabled children,

qualitative, self-care,

transition

Correspondence:

Susan Kirk, PhD, MSc,

BNurs, RN, RM, RHV, DN

Cert., School of Nursing,

Midwifery and Social

Work, University of

Manchester, University

Place, Oxford Road,

Manchester M13 9PL, UK

E-mail:

sue.kirk@manchester.ac.uk

\begin{abstract}
Background The disabled child population now incorporates a group of children and young people with complex healthcare needs, many of whom are supported by medical devices and technologies. Little is known about their experiences and perspectives, particularly in relation to transitions. Methods Twenty-eight young people aged between 8 and 19 years old were recruited via Community Children's Nursing Teams. Data were collected by in-depth qualitative interviews and analysed using Grounded Theory principles and procedures.

Results Young people with complex healthcare needs experience multiple and often concurrent transitions in their lives. As well as moving from childhood to adulthood, they experience different organizational and illness transitions. This paper focuses on their experiences of moving from children to adult services and moving from parental care to self-care. Moving to adult services was characterized as a time of uncertainty because of lack of information and involvement in transition planning. Concerns were expressed about the continuity of support packages into adult services and whether specialist expertise would be available. Young people in adult services described how they had needed to adjust to a different culture and way of working and the loss of relationships with familiar, trusted professionals. In addition to becoming socially independent, young people were in the process of acquiring control over their healthcare and support needs. The acquisition of responsibility for managing therapies and devices was described as an evolving, individually negotiated process. However, responsibility for decision-making and liasing with services could be acquired suddenly on transfer to adult services and not as part of an integrated self-care transition process.

Conclusions Transition is often too focused on service transition and transfer rather than conceptualizing it holistically as part of the process of moving to adulthood and independence. Young people with complex healthcare needs may have support needs that are unfamiliar for adult services at present. Multi-agency personalized planning that involves parents and young people is essential to ensure continuity of support and integration with other life transitions.
\end{abstract}

\section{Introduction}

The disabled child population is increasing in size and complexity of need as a result of medical advances (Sloper \& Beresford 2006). While there is no accepted definition of the term 'complex healthcare needs', it is generally used to describe children with ongoing healthcare needs related to the use of medical technology and who require the support of a range of professionals and agencies (Glendinning et al. 2001; Abbott et al. 2005). In recent years, research has illuminated parents' 
experiences of caring for children with complex healthcare needs, their experiences of support and the financial costs to families and services (Kirk \& Glendinning 2004; McKeever \& Miller 2004; Abbott et al. 2005; Heaton et al. 2005; Rehm \& Bradley 2005; Carnevale et al. 2006; Noyes et al. 2006). However, little is known about the perspectives of young people themselves, in particular in relation to how they experience different transitions. Moreover, because children with complex healthcare needs are a relatively new group of children who are surviving into adulthood, they are only just beginning to be transferred to adult services.

In terms of service transitions, consistently reported difficulties that young disabled people and those with long-term conditions experience include a lack of effective multi-agency assessment, planning and co-ordination between children and adult services; the lack of key/transition workers to co-ordinate transition; the use of different transition age points by different services (Rosen 1995; Viner 1999; Forbes et al. 2002; Morris 2002; Beresford 2004; Townsley 2004; While et al. 2004; Lotstein et al. 2005). Studies have noted the lack of equivalent adult services, the lack of specialist expertise in adult services and the loss of the school as the focus of provision (Fiorentino et al. 1998; Morris 1999; Reiss \& Gibson 2002; Tuffrey \& Pearce 2003; Lotstein et al. 2005). In addition, adult and children services are organized differently and have different cultures (Rosen 1995; Townsley 2004). It has been suggested that adult services are disinterested in transition issues (Scal et al. 1999; Reiss \& Gibson 2002). Some of these difficulties may account for reports of declining clinic attendance and deteriorating health status following transition (Kipps et al. 2002; Social Care Institute for Excellence 2004; Department of Health/Department for Education \& Skills 2006).

Young people may be inadequately involved in transition planning and lack information about the choices available to them (Fiorentino et al. 1998; Morris 2002; Beresford 2004). Little attention may be paid to what is important to them and their aspirations (Beresford 2004). Consequently, they and their parents can feel anxious about moving to adult services and reluctant to end long-standing relationships with professionals (Lotstein et al. 2005).

The need to improve transition has been recognized internationally (American Academy of Pediatrics et al. 2002; Royal College of Paediatrics and Child Health 2003; Royal College of Nursing 2004; Office of the Deputy Prime Minister 2005; Prime Minister's Strategy Unit 2005; Department of Health/ Department for Education and Skills 2006). Recent UK policy guidance has a common theme of providing co-ordinated, holistic, person-centred transition planning based on informed choice (Department of Health \& Department for Education and Skills 2004; Department of Health \& Department for Education and Skills 2006; Department for Children Schools and Families et al. 2007). However, there is a lack of research on the effectiveness of different models of transition support and on young people's perspectives (Rosen et al. 2003; Beresford 2004; While et al. 2004; McDonagh \& Viner 2006). Indeed, there is a lack of robust evidence on which to develop service models and interventions although important components of effective transition services have been identified (Rosen et al. 2003; Beresford 2004; While et al. 2004; McDonagh \& Viner 2006; McDonagh et al. 2006). While recent research suggests that transitional care programmes can be acceptable, useful and feasible to provide (McDonagh et al. 2006), few studies take a holistic view of transition, focusing instead on one aspect of the process within a single agency or describing transition services in relation to a specific medical condition (Nasr et al. 1992; Telfair et al. 1994; Scal et al. 1999; Flume et al. 2001).

The difficulties surrounding organizational transfers are compounded by concurrent status and life transitions as young people move towards adulthood and independence (Forbes et al. 2002; Beresford 2004). Moving into paid employment, financial independence, independent living, adult social relationships and parenthood may be difficult to attain for disabled young people (Hirst \& Baldwin 1994; Riddell 1998; Morris 1999, 2002; Hendey \& Pascall 2002; Beresford 2004; Townsley 2004). In addition, they face multiple barriers to independence, such as lack of personal support, inaccessible transport (Morris 1999, 2002). Incorporated within notions of transition and independence is young people's acquisition of autonomy over decision-making. For many young people with long-term conditions, transition will also involve acquiring responsibility for managing their health although this is a relatively underresearched area (Karlson et al. 2006; Schilling et al. 2006; Williams et al. 2007).

\section{Methods}

The focus of this paper is on how young people with complex healthcare needs experienced different transitions. This was one aspect of a wider study investigating young people's experiences of living with medical technology.

\section{The sample}

Twenty-eight young people were recruited via Community Children's Nursing teams in North-West England. Young people were purposively sampled to incorporate a range of ages 
Table 1. Healthcare technologies used by the young people in the sample $(n=28)$

\begin{tabular}{lc}
\hline Technology need & Number \\
\hline Gastrostomy/jejunostomy & 19 \\
Intravenous drug therapies & 7 \\
Mechanical ventilation & 6 \\
Tracheostomy & 4 \\
Oxygen therapy & 4 \\
Parenteral nutrition & 1 \\
Peritoneal dialysis & 1 \\
\hline
\end{tabular}

Table 2. Characteristics of the young people in the sample $(n=28)$

\begin{tabular}{lc}
\hline Characteristic & Number \\
\hline Gender & \\
Male & 17 \\
Female & 11 \\
Age (years) & \\
$8-11$ & 9 \\
$12-15$ & 11 \\
$6-19$ & 8 \\
Education/work & \\
Mainstream primary school & 6 \\
Special education primary school & 2 \\
Mainstream secondary school/college & 5 \\
Special education secondary school/college & 9 \\
Work & 1 \\
Further/higher education & 2 \\
Unemployed & 2 \\
Other & 1
\end{tabular}

and medical technologies. Tables 1 and 2 provide details of the participants' medical technology needs and socio-demographic characteristics.

\section{Data collection}

Face-to-face, in-depth interviews were conducted with young people in their homes. Where young people did not use verbal communication or alternative communication systems, parents were key informants on their children's lives and experiences $(n=9)$. An interview guide was used for the general direction of the interviews but participants were encouraged to direct the conversation into areas of importance for them. All interviews were recorded and transcribed verbatim.

\section{Data analysis}

Principles and procedures of the constant comparative method guided analysis (Strauss \& Corbin 1998; Charmaz 2006). Concurrent data collection and analysis occurred with codes and categories being inductively developed from the data. Analysis involved identifying codes, grouping codes to create categories, systematically comparing and contrasting categories and examining connections between categories.

\section{Ethical issues}

Ethical approval was obtained from a National Health Service research ethics committee. Information sheets were developed to be appropriate for a range of ages and needs. Parental consent to send information to young people under 16 years of age was obtained. Written consent/assent to participate was obtained from children/young people and parents at the time of the interview. Participants were assured of confidentiality and anonymity.

\section{Results}

Young people described experiencing multiple and sometimes concurrent transitions. Against a backdrop of moving from childhood to adulthood and the associated status changes, they could be navigating both organizational and illness transitions. Organizational transitions incorporated moving from primary to secondary education; from school into further/higher education or employment; from children's health services to adult health services (in both hospital and community sectors); and from children social care services to adult social services. Illness transitions involved moving from parent-led care to self-care, adapting to new technologies, and for some young people, coping with a deteriorating condition. This paper will focus on two of these transitions - moving to adult services and moving to self-care and independence.

\section{Moving to adult services}

Young people were at different stages in the process of being transferred to adult services and for some young people transfer was occurring at the same time as other transitions in their lives such as starting work or university. Managing these concurrent life changes meant that life was full of uncertainties.

\section{Going into the unknown}

Although some participants reported that transfer to adult services had been discussed during an educational review meeting or a consultation with a community or hospital paediatrician, formalized transition planning appeared to be absent. The parents of young people with high support needs reported 
having a lack of information about transition, particularly about the future options for their children after leaving school.

It's all mixed up, and nobody's talking to anybody else, you don't know what's available ... the information isn't offered, you know..., nobody's sort of like, comes forward with the information to you, they're very, very cagey with everything. So we'll just have to see what happens. (mother of Steven)

Parents could feel that their children were being steered towards residential care or it was presented to them as their only option.

they do want us to go and look at residential, they said we've got to go and look at it, even if we don't go, in case we change us mind, but I don't really want him to go. (mother of Callum)

While young people described being aware of their inevitable departure from children's services, transfer could come unexpectedly as they had not been involved in planning. One young person described his feelings of shock at the realization that he had been transferred to the adult hospital.

we went to a meeting at the [adult hospital], and it was kind of like an appointment as well, and it was like, 'this is Dr Smith, he's your consultant now, and he will be taking over your care from today'. 'So I'm a patient of the [adult hospital] now?' 'Yeah.' 'So I can't go to [children's hospital] now?' 'No'. And that was it. . . . when I came out with me Mum, 'so that's it then?' 'Yeah.' And it was like well, 'what if I'm unwell, where do I go now?' ... so it could have been better planned really ... it was just very sudden, which was a bit of a shock, you know. (Adam)

Some participants were aware that there would be no equivalent adult health service for them to transfer to and consequently were uncertain how their needs would be met in the future. Participants were also concerned about whether adult health and social care services would have the expertise to support young people with complex healthcare needs.

Participants in the midst of multi-agency transitions spoke of being in 'no man's land' or in 'limbo' as they were uncertain about where to seek support from and confused by the different age points for transfer used by different services.

we'll be on a learning curve to see which pigeonhole we fall into, whether it would be that District Nurses just take care of the gastrostomy, and the other aspects are social services, I don't know, so that's a grey area really... I mean from the gastrostomy point of view we've been in a bit of a confusion with whether we've fell under the community paediatric team, or whether it's the adult team, because it was the adult team that sort of put in the gastrostomy. (mother of Steven)

The parent of one young person who was in the process of being transferred to adult services described the uncertainty they were experiencing because of the reassessment of her son's care package and their fears that this would result in the loss of their familiar home support team.

\section{Going into a different world}

Young people who had transferred to adult health services contrasted children and adult services, highlighting what they saw as benefits and drawbacks of each and the cultural differences to which they had to adjust. Children services, including special schools, were described as protective, warm environments where they were 'cossetted' and 'cocooned'. In contrast, the environment of adult hospitals was described as threatening and depersonalized. Young people described how they appeared gloomy and dingy in comparison with the brightly coloured children wards and clinics. For those young people who had been admitted to an adult ward, the experience had been one of shock and adjustment to a different 'world'. When admitted to a children ward, they were used to their parents staying with them and having additional support from nurses and play therapists, whereas being hospitalized on an adult ward was quite different.

At a children's hospital, you don't feel like you're in hospital, but it's quite, I don't know, it's more, oh it's, nurses talk to you, and I know like people say I don't want to be talked to like I'm a kid, but I quite like that, because they're always like, you know, they're extra enthusiastic, and extra considerate. But when you're, when I was in an adult hospital I felt like, I don't know, I was really unhappy. (Poppy)

An important difference between children and adult health services related to how their status had changed following transfer. They described how professionals now saw them as adults and as a result they had to adjust to their involvement in decision-making being encouraged. The underlying philosophy had changed from family-centred to young person-centred care.

At the Paediatric centre they'd talk to the parents and say, you must make sure your child takes medication. At the adult centre, like they tell you the benefits of it, they tell you what happens if you don't take it, and leave it in your 
hands so, they give you a lot of control ... they do talk to you like you're an adult, it is your decision. It's like if you're not taking any certain medication like, are you taking everything, if not, you know, we're not going to start lecturing you, we're not going to start telling your parents to make sure you take it, it's up to you whether you take it not, but we're telling you how it benefits you. (Poppy)

they were only listening to you because they have to kind of thing, with some of them, but I guess because it was a children's hospital, the patient, all patients were children, and all doctors were adults, whereas in the [adult hospital] it's, everyone is an adult, so it's more of an equal sort of thing... I tend to speak up for a lot, a lot more for myself when I'm there now, because my Mum used to do all the talking for me because I used to just sit there and say nothing, because I was very shy and stuff when I was younger, and I didn't like to say anything, but now I have to, but I think it, in a way though it's, it's partly because my Consultant as well is dead friendly, and wants to know what I think as well. (Adam)

\section{Disrupted relationships and ways of working}

Participants spoke about their feelings of loss because of their relationships with trusted professionals coming to an end.

they are like friends, and I always get, 'hiya, how are you', and I sit there, and I always chat to them all. And like they all know me, and they'll talk to me, and 'hey, are you all right, are you all right?' And it's like a comfort zone for me, walking in, you know everyone, and you trust them looking after you, and if you have any problems I could go talk to them, about anything, it might be I'm unsure about my treatment, or I'm upset about something, and I can talk to them. Whereas when you move to [the adult hospital], like you don't know anyone, and how it's going to be. (Brittany)

As well as the loss of long-standing relationships, participants had to adjust to different ways in which support was organized and provided in adult services. Moving to adult healthcare services could also lead to changes in equipment and therapy regimens as one participant explained.

From the age of like 13, I think it was, I had regular IV's, and when I started at the Adult Centre, they told me that they don't normally do routine ones straightaway. They like to see how the individual gets on without them, and then work out their own pattern. So I was a bit, not concerned, but from knowing that I have them every 3 months, to knowing that I didn't know when I was going to get my next lot. (Poppy)

For the participants in this study, moving to adult services was marked by feelings of uncertainty and loss. Uncertainty was a consequence of a lack of information and involvement in the planning process. While losses were described in relation to the loss of familiar staff and ways of working with services, young people's autonomy was encouraged in adult services as a result of young people being redefined as adults.

\section{From parental care to self-care}

Another transition young people experienced was their developing independence from their parents. As well as becoming increasingly socially independent, young people were in the process of acquiring control over their healthcare and support needs.

\section{Managing therapies and devices}

In relation to managing the medical technologies, young people described a gradual process of moving from parental responsibility through a period of shared responsibility to self-care, with different activities being transferred at different times.

We both used to do it, and then like it would start off now and again I'd do it, if me Mum was out or now and again I'd do it at a weekend, and me Mum would supervise, and then it gradually got to me doing it unsupervised, and then doing it every other night like, and then every night unless I was unwell, then me Mum would do it, which is what it is now. I do it every night unless I'm unwell. (Adam)

Mum does [mixes] it, but the feed, sometimes I put it up myself. (Ben)

However, it was apparent that this was not a unidirectional process as during times when the young person was unwell, tired or lacking self-motivation, parents would takeover caring activities. Indeed, parents continued to play a 'coaching' role, encouraging and supporting young people in relation to selfcare even after they had transferred to adult services or left the family home.

The transfer of responsibility for managing therapies and devices from parents to young people was an individualized process that was negotiated between the parent and the young person and either parent or young person could initiate this 
process. However, this could be a time of discord while parents relinquished control and developed trust in their child's selfcare abilities. Young people in their late teens, who reflected on the conflict they had experienced with their parents at this time, normalized these tensions as being an extension of teenagers' conflicts with parents.

I remember when I was $15,16,17$, I did not want to do it at all, it was like, no I'm going out, I want to go out, and I'd go out, or, I don't want to do it, so I'm not doing it, And then, the other thing that's happening when you're 16 , you tend to rebel anyway when you're 16 , I'm not doing it, because she said I have to do it, but as you get older you do. (Brittany)

Young people's involvement was not necessarily determined by their age or whether they had a learning disability. Both young children and young people with a learning disability were involved in managing elements of the therapies and devices they needed.

Transfer appeared from young people's accounts to be influenced by their own readiness to accept responsibility. This could be influenced by their perceptions of the risks attached to particular procedures.

I am pushing like the flushes through and that. Like seeing how it is and that. My Mum does it if I need antibiotics because I don't want to do it ... It's a big thing, isn't it? It's going, when it goes in it's going past the heart, so if I get it wrong then. (Paris)

Young people could feel reluctant to become involved in therapies and procedures because they found them unpleasant in terms of the associated sensations such as the smell of the feeds or the appearance of device.

Taking on responsibility for therapies and devices enabled young people to gain independence from their parents, as they were then able to care for themselves outside the home. If young people needed therapies during the school day, then this was an additional incentive to encouraging the transfer of responsibility from parent to young person.

Young people's accounts presented professionals as playing a peripheral role in their transition to self-care. Their knowledge about how to manage their condition appeared to come from their parents. However, some parents described the encouragement that professionals had given them in promoting their child's autonomy or in setting the parameters for their child's self-management.

Some young people's impairments meant that they continued to need the support of others in managing devices.
Support workers with the expertise to care for young people with complex healthcare needs and who provided support in a flexible, person-centred way were seen as giving young people an opportunity to experience an independent social life.

\section{Making decisions}

For most young people, their involvement in performing procedures or parts of procedures appeared to occur before their involvement in actual decision-making about their healthcare. As young people developed expertise in managing the therapies/devices and in 'knowing their own body', they were able to make adjustments to regimens in order to integrate them into their everyday lives.

As presented earlier in the paper, interactions with professionals were described as being largely parent-focused until transfer to adult services. While some participants were happy with this situation, there were others (largely teenagers) who would have liked more involvement.

Some doctors talk to me, some just, you talk to them, and they ignore me, they just go to me Mum, and I wouldn't be there to them sort of thing, and it's like, if I want to say something, I'd have to tell me Mum to say it, because they just wouldn't listen to me or they wouldn't answer me face-to-face, they'd talk to me Mum instead . . . It makes me feel annoyed because I'm the one who's unwell and it's not like I'm young and I don't understand what they're saying anymore. It's like um, I, I've asked you the question, I want to know what's the matter. (Ray)

Sometimes they talk to me. They just ask how I'm feeling and that... Mostly it's my Mum what does the questions, and my Mum asks me if I want to ask anything. And my Mum will say it on my behalf, instead of me saying it. (Paris)

Although young people's impairments could constrain their self-care roles in relation to psycho-motor skills such as using devices, their impairments did not prevent them from involvement in decision-making relating to their health care and other aspects of their lives. One young person was supported by an independent advocate at meetings with professionals and in making decisions in relation to his life such as making a will. For those young people who did not communicate verbally or use communication aids, parents described how they paid close attention to their non-verbal communication such as their behaviour, facial expressions and noises to assess their wishes. They then used their interpretations in decision-making on 
their child's behalf and in promoting their control over aspects of their lives.

\section{Negotiating the healthcare system and accessing resources}

Until young people moved to adult services, parents appeared to play an intermediary role with the service system. Although young people could be playing a central role in managing their condition, parents continued to negotiate service support and liase with professionals on their child's behalf. Following transfer, young people had to adjust to directly managing the service system. This involved going alone to appointments, accessing support when they were ill, staying in hospital by themselves and organizing the provision of equipment and supplies.

For the young people in this study, transition incorporated the transfer of responsibility for managing their health care and support from parents to themselves. While the acquisition of responsibility for managing therapies and devices was described as an evolving, individually negotiated process, responsibility for decision-making and liasing with services could be acquired suddenly on transfer to adult services and not as part of an integrated self-care transition process.

\section{Conclusion}

A growing body of research and policy has recommended how transition should be managed in terms of ensuring multiagency person-centred planning; co-ordination and continuity; involvement of young people and families; and dedicated transition support. In recent years, numerous transition pathways and guides have been developed emphasizing these characteristics (e.g. Royal College of Nursing 2004; Sholl et al. 2005; ACT 2007; Department for Children Schools and Families, 2007). These principles and practice guides are the foundations on which all transition planning and support should be based. For young people with complex healthcare needs, person-centred assessment and planning is particularly important within health service specialities and sectors as well as at a multi-agency level. Many have conditions and support needs that are unfamiliar to adult services; hence, both adult and children service need to work together. Indeed, some young people are supported by costly and complex home support packages for which multiagency planning is crucial in ensuring continuity of support and integration with other life transitions. Intermediate services that cross children and adult service cultures have been proposed in the health sector and this may be an appropriate way of organizing services where young people have life-limiting conditions (Tuffrey \& Pearce 2003). As this group of young people have only relatively recently begun to survive into adulthood, there is a lack of research on effective ways of organizing service transfers.

There is a danger that transition is too focused on service transfer rather than it as one element of a young person's move to adulthood. This would enable the transfer to adult services to be seen more positively and consistent with reaching adulthood, as an event that is expected and desirable and where they are supported in ending long-term relationships (Reiss \& Gibson 2002).

Transition also encompasses changes in roles, relationships and status as the young person gains independence and autonomy. In this study, young people's relationships with parents and professionals changed as their role in decisionmaking and managing their condition extended. However, it was evident that young people were not well prepared during their time in children services for becoming increasingly involved in decision-making and in consultations with professionals or for becoming responsible for elements of service organization. This area needs to be incorporated into transition planning and for some young people access to the support of independent advocates may be appropriate.

Children services have found it challenging to provide appropriate support for this group of young people (Kirk \& Glendinning 2004) and there is a danger that these experiences will be repeated within adult services and what has been learned in recent years lost, unless there is appropriate and proactive multi-agency service planning and provision that fully involves parents, young people and service providers from both child and adult agencies.

\section{Key messages}

- Young people with complex healthcare needs experience multiple and sometimes concurrent transitions.

- Young people and parents appear to be inadequately prepared for and involved in service transition.

- They are concerned about continuity of support and expertise in supporting people with complex healthcare needs in adult services.

- The transfer of responsibility for decision-making and liasing with services should form part of an integrated self-care transition process.

- Research is needed to investigate how to effectively support young people with complex healthcare needs through the complex network of transitions they navigate. 


\section{References}

Abbott, D., Townsley, R. \& Watson, D. (2005) Multi-agency working in services for disabled children: what impact does it have on professionals? Health and Social Care in the Community, 13, 155-163.

Association for Children's Palliative Care (ACT) (2007) The Transition Care Pathway: A Framework for the Development of Multi-agency Care Pathways for Young People with Life-Threatening and Life Limiting Conditions. ACT, Bristol, UK.

American Academy of Pediatrics, American Academy of Family Physicians, American College of Physicians - American Society of Internal Medicine (2002) Consensus statement on health care transitions for young adults with special health care needs. Pediatrics, 110, 1304-1306.

Beresford, B. (2004) On the road to nowhere? Young disabled people and transition. Child: Care Health Development, 30, 581-587.

Carnevale, F., Alexander, E., Davis, M., Rennick, J. \& Troini, R. (2006) Daily living with distress and enrichment: the moral experience of families with ventilator-assisted children at home. Pediatrics, 117, $48-60$.

Charmaz, K. (2006) Constructing Grounded Theory: A Practical Guide through Qualitative Analysis. Sage, London, UK.

Department for Children Schools and Families, D.o.H., Council for Disabled Children, National Children's Bureau (2007) A Transition Guide for All Services: Key Information for Professionals about the Transition Process for Disabled Young People. Department for Children, Schools and Families, London, UK.

Department of Health, Department for Education and Skills (2004) The National Service Framework for Children, Young People and Maternity Services: Disabled Child. Department of Health, London, UK.

Department of Health, Department for Education and Skills (2006). Transition: Getting it Right for Young People. Department of Health, London, UK.

Fiorentino, L., Phillips, D., Walker, A. \& Hall, D. (1998) Leaving paediatrics: the experience of service transition for young disabled people and their family carers. Health and Social Care in the Community, 6, 260-270.

Flume, P., Anderson, D., Hardy, K. \& Gray, S. (2001) Transition programs in cystic fibrosis centers: perceptions of pediatric and adult program directors. Pediatric Pulmonology, 31, 443-450.

Forbes, A., While, A., Ullman, R., Lewis, S., Mathes, L. \& Griffiths, P. (2002) A Multi-method Review to Identify Components of Practice Which May Promote Continuity in the Transition from Child to Adult Care for Young People with Chronic Illness or Disability. Kings College London, London, UK.

Glendinning, C., Kirk, S., Lawton, D. \& Guiffrida, A. (2001) Technology dependent children in the community: definitions, numbers and costs. Child Care Health Development, 27, 321-334.

Heaton, J., Noyes, J., Sloper, P. \& Shah, R. (2005) Families' experiences of caring for technology-dependent children: a temporal perspective. Health and Social Care in the Community, 13, 441-450.

Hendey, N. \& Pascall, G. (2002) Becoming Adult: Young Disabled People Speak. Joseph Rowntree Foundation, York, UK.

Hirst, M. \& Baldwin, S. (1994) Unequal Opportunities: Growing up Disabled. Social Policy Research Unit, University of York, York, UK.

Karlsson, A., Arman, M. \& Wikblad, K. (2006) Teenagers with type 1 diabetes: a phenomenological study of the transition towards autonomy in self-management. International Journal of Nursing Studies, 45, 562-570.

Kipps, S., Bahu, T., Ong, K., Ackland, F., Brown, R., Fox, C., Griffin, N., Knight, A., Mann, N., Neil, H., Simpson, H., Edge, J. \& Dunger, D. (2002) Current methods of transfer of young people with type 1 diabetes to adult services. Diabetic Medicine, 19, 649-654.

Kirk, S. \& Glendinning, C. (2004) Developing services to support parents caring for a technology-dependent child at home. Child Care Health Development, 30, 209-218.

Lotstein, D., McPherson, M., Strickland, B. \& Newacheck, P. (2005) Transition planning for youth with special health care needs: results from the national survey of children with special health care needs. Pediatrics, 115, 1562-1568.

McDonagh, J. \& Viner, R. (2006) Lost in transition: between paediatric and adult services. British Medical Journal, 332, 435-436.

McDonagh, J., Shaw, K. \& Southwood, T. (2006) Growing up and moving on: development and preliminary evaluation of a transitional care programme for a multicentre cohort of adolescents with juvenile idiopathic arthritis. Journal of Child Health Care, 10, 22-42.

McKeever, P. \& Miller, K. (2004) Mothering children who have disabilities: a Bourdieusian interpretation of maternal practices. Social Science \& Medicine, 59, 1177-1191.

Morris, J. (1999) Hurting into the Void: Transition to Adulthood for Young Disabled People with Complex Health and Support Needs. Pavilion Publishing, Brighton, UK.

Morris, J. (2002) Moving into Adulthood. Joseph Rowntree Foundation, York, UK.

Nasr, S., Campbell, C. \& Howatt, W. (1992) Transition program from pediatric to adult care for cystic fibrosis. Journal of Adolescent Health, 13, 682-685.

Noyes, J., Godfrey, C. \& Beecham, J. (2006) Resource use and service costs for ventilator-dependent children and young people in the UK. Health and Social Care in the Community, 14, 508-522.

Office of the Deputy Prime Minister (2005) Improving Services, Improving Lives. Social Exclusion Unit, London, UK.

Prime Minister's Strategy Unit (2005) Improving the Life Chances of Disabled People. The Cabinet Office Strategy Unit, London, UK.

Rehm, R. \& Bradley, J. (2005) Normalisation in families raising a child who is medically fragile/technology dependent and developmentally delayed. Qualitative Health Research, 15, 807-820.

Reiss, J. \& Gibson, R. (2002) Health care transition: destinations unknown. Pediatrics, 110, 1307-1314.

Riddell, S. (1998) The dynamic of transition to adulthood. In: Growing up with Disability (eds. C. Robinson \& K. Stalker), pp. 189-209. Jessica Kingsley Publisher, London. 
Rosen, D. (1995) Between two worlds: bridging the cultures of child health and adult medicine. Journal of Adolescent Health, 17, 10-16.

Rosen, D., Blum, R., Britto, M., Sawyer, S. \& Siegel, D. (2003) Transition to adult health care for adolescents and young adults with chronic conditions: position paper of the society for adolescent medicine. Journal of Adolescent Health 33, 309-311.

Royal College of Nursing (2004) Adolescent Transition Care. Royal College of Nursing, London, UK.

Royal College of Paediatrics and Child Health (2003) Bridging the Gap Health Care for Adolescents. Royal College of Paediatrics and Child Health, London, UK.

Scal, P., Evans, T., Blozis, S., Okinow, N. \& Blum, R. (1999) Trends in transition from pediatric to adult health care services for young adults with chronic conditions. Journal of Adolescent Health, 24, 259-264.

Schilling, L., Knafl, K. \& Grey, M. (2006) Changing patterns of self-management in youth with type 1 diabetes. Journal of Pediatric Nursing, 21, 412-423.

Sholl, C., Dancyger, F., Parsons, M. \& Dale, C. (2005) Transition pathway: guidance and tools to support person centred transition planning with young disabled people aged 13-25. Transition Pathway Partnership. Available at: http://www.transitionpathway.co.uk/ (accessed from 13 June 2008).

Sloper, P. \& Beresford, B. (2006) Families with disabled children. British Medical Journal, 333, 928-929.

Social Care Institute for Excellence (2004) Transition of Young People with Physical Disabilities or Chronic Illnesses from Children's to Adult's Services. Social Care Institute for Excellence, London, UK.
Strauss, A. \& Corbin, J. (1998) Basics of Qualitative Research: Techniques and Procedures for Developing Grounded Theory. Sage, Thousand Oaks, CA, USA.

Telfair, J., Myers, J. \& Drezner, S. (1994) Transfer as a component of the transition of adolescents with sickle cell disease to adult care: adolescent, adult and parent perspectives. Journal of Adolescent Health, 15, 558-565.

Townsley, R. (2004) The Road Ahead? A Literature Review. Norah Fry Research Centre, Bristol, UK.

Tuffrey, C. \& Pearce, A. (2003) Transition from paediatric to adult medical services for young people with chronic neurological problems. Journal of Neurology, Neurosurgery and Psychiatry, 74, 1011-1013.

Viner, R. (1999) Transition from paediatric to adult care: bridging the gap or passing the buck? Archives of Disease in Childhood, 81, 271-275.

While, A., Forbes, A., Ullman, R., Lewis, S., Mathes, L. \& Griffiths, P. (2004) Good practices that address continuity during transition from child to adult care: systhesis of the evidence. Child: Care Health Development, 30, 439-452.

Williams, B., Mukhopadhyay, S., Dowell, J. \& Coyle, J. (2007) From child to adult: an exploration of shifting family roles and responsibilities in managing physiotherapy for cystic fibrosis. Social Science \& Medicine, 65, 2135-2146. 